\title{
Evaluasi Layanan Bimbingan Teknologi Informasi dan Komunikasi (TIK)
}

\section{Sri Marina Gusti ${ }^{*}$, Ambiyar $^{2}$}

1,2 Program Studi Magister Teknologi dan Kejuruan, Universitas Negeri Padang, Padang, Indonesia

\section{A R T I C L E I N F O}

\section{Article history:}

Received August 26, 2021

Revised August 28, 2021

Accepted September 30, 2021

Available online December 25, 2021

Kata Kunci:

Evaluasi, Bimbingan TIK,

Kirkpatrick

Keywords:

Evaluation, ICT Guidance, Kirkpatrick

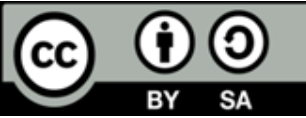

This is an open access article under the CC BY-SA license.

Copyright (ㄷ) 2021 by Author. Published by Universitas Pendidikan Ganesha.

\begin{abstract}
A B S T R A K
Pelaksanaan layanan TIK belum maksimal. Beberapa sekolah belum memiliki fasilitas penunjang untuk melaksanakan layanan bimbingan TIK seperti masih kurangnya perangkat komputer di sekolah dan tidak adanya akses internet. Hal ini mengakibatkan kurangnya pemahaman dan pemanfaatan teknologi pada peserta didik. Penelitian ini bertujuan untuk mengevaluasi pelaksanaan layanan bimbingan TIK pada siswa. Layanan bimbingan TIK yang dilakukan di sekolah dimaksudkan untuk mempersiapkan peserta didik agar mampu mengantisipasi pesatnya perkembangan teknologi, sehingga peserta didik dapat memanfaatkan TIK dengan baik dan benar sesuai dengan keahliannya. Penelitian ini adalah penelitian evaluasi dengan pendekatan kuantitatif menggunakan model penelitian evaluasi Kirkpatrick dengan empat level tahapan evaluasi, yaitu level reaksi, pembelajaran, perilaku, dan hasil. Subjek pada penelitian ini adalah peserta didik yang sedang mengikuti layanan bimbingan TIK. Teknik pengambilan data melalui kuesioner/angket. Hasil analisis data menunjukkan bahwa ketercapaian layanan bimbingan TIK pada komponen level 1 reaksi sebesar $71,46 \%$ dengan kategori baik, komponen level 2 pembelajaran sebesar $74,41 \%$ dengan kategori baik, komponen level 3 perilaku sebesar $72 \%$ dengan kategori baik, dan komponen level 4 hasil sebesar $74,73 \%$ dengan kategori baik. Dengan demikian dapat disimpulkan bahwa layanan bimbingan TIK pada peserta didik dikategorikan baik pada semua variabel pengukuran.
\end{abstract}

\section{A BST RACT}

Implementation of ICT services has not been maximized. Some schools do not yet have supporting facilities to provide ICT guidance services, such as the lack of computer equipment in schools and the absence of internet access which results in a lack of understanding and use of technology in students. This study aims to implement the implementation of ICT guidance services to students. ICT guidance services are carried out in schools to prepare students to anticipate the rapid development of technology to use ICT correctly and adequately according to their expertise. This research is evaluation research with a quantitative approach with Kirkpatrick's evaluation model with evaluation stages, namely the level of reaction, learning, behavior, and results. The subjects in this study were students who were following ICT guidance services. The technique of collecting data is through a questionnaire/questionnaire. The results of data analysis are the achievement of ICT guidance services at the level 1 component of the reaction by $71.46 \%$ in the good category, the level 2 learning component by $74.41 \%$ in the good category, the behavioral level 3 component by $72 \%$ in the good category, the level 4 component results by $74.73 \%$ with good category. Thus it can be said that ICT guidance services to students are good on all measurement variables.

\section{PENDAHULUAN}

Konsep kurikulum 2013 menekankan pada aspek kognitif (pengetahuan), afektif (sikap), dan psikomotorik (gerak) melalui penilaian berbasis test dan portofolio (Andrian \& Rusman, 2019; Febriyanti, 2013; Susanti et al., 2015). Saat ini peserta didik tidak lagi menjadi objek pendidikan, tetapi dituntut menjadi subjek dengan ikut aktif, kreatif, dan inovatif dalam setiap pemecahan masalah yang mereka 
hadapi dalam pembelajaran (Mulyadin, 2016; Nasihin, 2016). Perubahan kurikulum yang dilakukan oleh pemerintah bertujuan untuk perbaikan sistem pendidikan. Namun, pada kenyataannya setiap kurikulum pasti memiliki kekurangan dan kelebihan yang perlu dievaluasi serta diperbaiki agar tujuan pendidikan nasional tercapai dengan baik (Sanjiwana et al., 2015). Penyusunan dan pelaksanaan kurikulum 2013 oleh satuan pendidikan harus memperhatikan kebutuhan, karakteristik, dan potensi satuan pendidikan (internal) serta lingkungan di daerah setempat (Maharani, 2015; Rahmawati et al., 2017).

Pemberlakuan kurikulum 2013 di Indonesia berdampak pada kesiapan dan peran guru dalam proses pembelajaran. Guru harus mencari, mengolah, menyiapkan, mendistribusikan, menyajikan, menginformasikan, serta memanfaatkan data dan informasi dalam berbagai cara untuk mendukung kelancaran proses pembelajaran untuk membimbing peserta didik, menggunakan TIK untuk persiapan, pelaksanaan, dan penilaian pembelajaran pada pendidikan dasar dan menengah guna memfasilitasi sesama guru, serta memfasilitasi tenaga kependidikan dalam menerapkan dan mengembangkan sistem informasi manajemen sekolah berbasis TIK (Astiningtyas, 2018; Tanudjaya \& Doorman, 2020). Dalam kurikulum 2013, Guru sudah tidak lagi mengajar seperti dalam kurikulum sebelumnya, akan tetapi guru berperan sebagai fasilitator dan penyedia layanan bimbingan berkaitan tentang TIK (Bdiwi et al., 2019; Mellom et al., 2018; Tseng, 2021). Layanan bimbingan TIK yang dilakukan di sekolah dimaksudkan untuk mempersiapkan peserta didik agar mampu mengantisipasi pesatnya perkembangan teknologi, sehingga peserta didik dapat memanfaatkan TIK dengan baik dan benar sesuai dengan keahliannya (Harliawan, 2015; Lubis, 2018). Namun layanan bimbingan TIK bukan hal yang mudah untuk diimplementasikan karena berhubungan dengan ketersediaan guru yang berkualifikasi akademik TIK, waktu pelaksanaan, sarana prasarana dan program layanan bimbingan TIK tersebut.

Pemasalahan yang terjadi saat ini yaitu pelaksanaan layanan TIK belum maksimal (Amelia et al., 2017; Eugenia et al., 2013). Permasalahan ini juga ditemukan pada salah satu sekolah menengah atas. Berdasarkan hasil observasi dan wawancara yang dilakukan di SMA Negeri Kabupaten Dharmasraya, ditemukan permasalahan yaitu pelaksanaan layanan bimbingan TIK pada peserta didik belum berjalan secara maksimal. Beberapa sekolah belum memiliki fasilitas penunjang untuk melaksanakan layanan bimbingan TIK, kurangnya perangkat komputer di sekolah, dan tidak adanya akses internet yang mengakibatkan kurangnya pemahaman dan pemanfaatan teknologi pada peserta didik. Waktu yang diberikan untuk pelaksanaan layanan bimbingan TIK sangat terbatas yaitu hanya dilakukan satu jam pelajaran tatap muka untuk setiap kelas per minggu, sehingga tidak semua materi bisa diterima oleh peserta didik. Kompetensi guru dalam menyampaikan materi TIK juga sangat diperlukan. Layanan bimbingan TIK di beberapa sekolah dilakukan oleh guru yang tidak berkualifikasi akademik TIK, sehingga materi bimbingan yang diberikan masih bersifat umum.

Solusi yang ditawarkan yaitu mengadakan evaluasi layanan bimbingan TIK. Hal ini bertujuan untuk mengetahui kekurangan pelaksanaan layanan bimbingan TIK, sehingga dapat mengatasi permasalahan tersebut. Layanan bimbingan TIK senantiasa dievaluasi untuk mengetahui sejauh mana program tersebut telah berhasil mencapai maksud pelaksanaan program yang telah ditetapkan. Evaluasi merupakan penentuan hasil nilai suatu hal, yang dapat meliputi informasi yang digunakan untuk memutuskan nilai keberhasilan suatu program, produk, prosedur, tujuan atau manfaat yang pada desain pendekatan alternative untuk mempertahankan tujuan khususnya (Enas Almanasreh et al., 2019; Tempelaar, 2019; Wu et al., 2019). Evaluasi merupakan suatu proses yang dapat menyediakan informasi yang dijadikan sebagai bahan pertimbangan untuk menentukan hasil nilai dan harga dari tujuan yang dicapai, desain, implementasi (Hanifa, 2018; Mulyanto et al., 2020). Hasil dari evaluasi dapat menjadi rekomendasi dalam membuat keputusan, membantu mempertanggung jawabkan, dan meningkatkan pemahaman terhadap fenomena (Almutairi \& Shraid, 2021; Peralbo-Uzquiano et al., 2020). Jadi, evaluasi dapat berarti penyediaan informasi yang dapat disajikan sebagai bahan pertimbangan dalam mengambil sebuah keputusan.

Model evaluasi yang dipilih dalam evaluasi layanan bimbingan TIK pada peserta didik adalah model evaluasi Kirkpatrick. Model ini menggunakan empat level dalam mengkategorikan hasil-hasil pelatihan. Empat level tersebut adalah level reaksi, pembelajaran, perilaku dan hasil (Bhatia et al., 2021; Savul et al., 2021). Model evaluasi yang dikembangkan oleh Kirkpatrick dikenal sebagai The Four Levels atau Kirkpatrick's model. Keempat level tersebut adalah sebagai berikut. 1) Reaksi dilakukan untuk mengukur tingkat reaksi yang didisain agar mengetahui opini dari para peserta pelatihan mengenai program pelatihan; 2) Pembelajaran mengetahui sejauh mana daya serap peserta program pelatihan pada materi pelatihan yang telah diberikan; 3) Perilaku diharapkan setelah mengikuti pelatihan terjadi perubahan tingkah laku peserta dalam melakukan pekerjaan; dan 4) Hasil untuk menguji dampak pelatihan terhadap kelompok kerja secara keseluruhan (Farjad, 2012; Gracieux, 2019). Temuan penelitian sebelumnya menyatakan bahwa model Kirkpatrick dapat digunakan sebagai evaluasi pelatihan (Sakthi \& Moshi, 2021; Yongliang et al., 2015). Temuan lainnya juga menyatakan bahwa model Kirkpatrick efektif 
digunakan dalam mengevaluasi suatu program (Bijani et al., 2018; Buriak \& Ayars, 2019). Dapat disimpulkan bahwa model Kirkpatrick dapat digunakan dalam evaluasi program. Tujuan penelitian ini yaitu untuk mengevaluasi pelaksanaan layanan bimbingan TIK pada peserta didik di SMA Negeri Kabupaten Dharmasraya. Diharapkan pelaksanaan layanan bimbingan TIK dapat membantu siswa.

\section{METODE}

Jenis penelitian ini yaitu kuantitatif. Penelitian ini merupakan penelitian evaluasi. Peneliti mengevaluasi layanan bimbingan TIK pada peserta didik di SMA Negeri Kabupaten Dharmasraya menggunakan model penelitian evaluasi Kirkpatrick dengan empat level tahapan evaluasi. Empat level tersebut adalah level reaksi, pembelajaran, perilaku dan hasil. Instrumen yang digunakan dalam pendekatan kuantitatif adalah kuesioner (angket). Setelah penyebaran instrumen, dilakukan analisis terhadap data yang telah diperoleh untuk mengetahui tingkat pencapaian responden pada setiap indikator. Hasil analisis data kuantitatif ini dilakukan untuk pengambilan kesimpulan dan rekomendasi dari setiap indikator. Sampel dalam penelitian ini adalah peserta didik kelas X (Sepuluh) yang mengikuti layanan bimbingan TIK tahun ajaran 2021/2022 pada SMA Negeri di Kabupaten Dharmasraya sebanyak 4 (empat) sekolah sebanyak 110 peserta didik. Teknik pengumpulan data dengan pendekatan kuantitatif yang digunakan dalam penelitian ini yaitu kuesioner (angket). Penelitian ini menggunakan angket tertutup, yaitu komunikasi dilakukan dengan cara tidak langsung. Kuesioner disusun berdasarkan model penelitian evaluasi Kirkpatrick dengan empat level tahapan evaluasi yaitu level reaksi, pembelajaran, perilaku, dan hasil dengan menggunakan skala likert yaitu dengan lima alternatif jawaban. Jawaban tersebut mempunyai skor minimal dan maksimal.

\section{HASIL DAN PEMBAHASAN}

Berdasarkan analisis deskriptif dari empat level tahapan evaluasi yaitu level reaksi, pembelajaran, perilaku, dan hasil diperoleh hasil pengukuran Evaluasi komponen level 1 reaksi pelaksanaan layanan bimbingan TIK di SMAN Kabupaten Dharmasraya terbagi berdasarkan lima bagian yang ditinjau yaitu, 1) fasilitas yang tersedia, 2) strategi penyampaian materi, 3) media pembelajaran, 4) jadwal kegiatan, dan 5) materi yang diberikan. Analisis deskriptif terhadap komponen level 1 reaksi yang terdiri dari lima indikator adalah sebagai berikut. Komponen level 1, reaksi ditinjau dari fasilitas yang tersedia, angket yang diberikan kepada 110 orang peserta didik diperoleh nilai rata-rata 3,76 dari skor maksimal 5 dengan tingkat pencapaian responden sebesar 75,21\% termasuk dalam kategori "baik", Artinya, fasilitas yang tersedia dalam layanan bimbingan TIK sudah baik .Komponen level 1, reaksi ditinjau dari strategi penyampaian materi, angket yang diberikan kepada 110 orang peserta didik diperoleh nilai rata-rata 3,75 dari skor maksimal 5 dengan tingkat pencapaian responden sebesar 74,91\% dalam kategori "baik". Artinya, strategi guru dalam penyampaian materi layanan bimbingan TIK sudah baik.

Komponen level 1, reaksi ditinjau dari media pembelajaran, angket yang diberikan kepada 110 orang peserta didik diperoleh nilai rata-rata 3,5 dari skor maksimal 5 dengan tingkat pencapaian responden sebesar 70\% dalam kategori "baik". Artinya, media pembelajaran yang digunakan oleh guru sudah bervariasi. Komponen level 1, reaksi ditinjau dari jadwal kegiatan, angket yang diberikan kepada 110 orang peserta didik diperoleh nilai rata-rata 3,31 dari skor maksimal 5 dengan tingkat pencapaian responden sebesar 66,23\% dalam kategori "baik". Artinya, waktu layanan sudah terjadwal dengan baik walaupun jadwal layanan hanya 1 jam pelajaran per minggu, sehingga tidak semua materi layanan bimbingan TIK dapat disampaikan. Komponen level 1, reaksi ditinjau dari materi yang diberikan, angket yang diberikan kepada 110 orang peserta didik diperoleh nilai rata-rata 3,55 dari skor maksimal 5 dengan tingkat pencapaian responden sebesar 70,97\% dalam kategori "baik". Artinya, materi yang diberikan, sudah sesuai dengan topik yang direncanakan pada program layanan bimbingan TIK.

Evaluasi komponen level 2, pembelajaran pelaksanaan layanan bimbingan TIK di SMAN Kabupaten Dharmasraya terbagi berdasarkan tiga bagian yang ditinjau yaitu, 1) Pengetahuan, 2) Keterampilan, dan 3) Sikap. Analisis deskriptif terhadap variabel masukan terdiri atas tiga indikator adalah sebagai berikut. Komponen level 2, pembelajaran ditinjau dari pengetahuan, angket yang diberikan kepada 110 orang peserta didik diperoleh nilai rata-rata 3,65 dari skor maksimal 5 dengan tingkat pencapaian responden sebesar 73,09\% dalam kategori "baik". Artinya, pengetahuan yang didapat dalam mengikuti layanan bimbingan TIK sudah baik dan sesuai dengan yang diharapkan oleh program layanan bimbingan TIK. Komponen level 2, pembelajaran ditinjau dari keterampilan, angket yang diberikan kepada 110 orang peserta didik diperoleh nilai rata-rata 3,65 dari skor maksimal 5 dengan tingkat pencapaian responden sebesar 73,09\% kategori "baik". Artinya, keterampilan yang dikembangkan dalam mengikuti layanan bimbingan TIK sudah baik dan sesuai dengan pengetahuan yang dimiliki. Komponen 
level 2, pembelajaran ditinjau dari sikap, angket yang diberikan kepada 110 orang peserta didik diperoleh nilai rata-rata 3,85 dari skor maksimal 5 dengan tingkat pencapaian responden sebesar 77,05\% dalam kategori "baik". Artinya, sikap dalam mengikuti layanan bimbingan TIK sudah baik. Peserta didik sangat antusias dalam mengikuti layanan bimbingan TIK.

Evaluasi komponen level 3, perilaku pelaksanaan layanan bimbingan TIK di SMAN Kabupaten Dharmasraya terbagi berdasarkan satu bagian yang ditinjau yaitu, perubahan sikap. Analisis deskriptif terhadap variabel proses yang terdiri dari satu indikator adalah sebagai berikut. Komponen level 3, perilaku ditinjau dari perubahan sikap, angket yang diberikan kepada 110 orang peserta didik diperoleh nilai rata-rata 3,62 dari skor maksimal 5 dengan tingkat pencapaian responden sebesar 72,32\%. dalam kategori "baik". Artinya, perubahan sikap setelah mengikuti layanan bimbingan TIK sudah baik, peserta didik tertarik untuk mengikuti layanan dan peserta didik bisa mengembangkan kemampuannya sesuai dengan pengetahuan yang dimiliki dalam bidang TIK. Evaluasi komponen level 4, hasil pelaksanaan layanan bimbingan TIK di SMAN Kabupaten Dharmasraya terbagi berdasarkan dua bagian yang ditinjau yaitu, 1) peningkatan pengetahuan dan 2) perbaikan keterampilan. Analisis deskriptif terhadap variabel produk yang terdiri dari dua indikator adalah sebagai berikut. Komponen level 4 hasil ditinjau dari peningkatan pengetahuan, angket yang diberikan kepada 110 orang peserta didik diperoleh nilai rata-rata 3,68 dari skor maksimal 5 dengan tingkat pencapaian responden sebesar 73,64\% dalam kategori "baik". Artinya, peningkatan pengetahuan dalam bidang TIK sudah baik, pengetahuan peserta didik bertambah setelah mengikuti layanan bimbingan TIK. Komponen level 4, hasil ditinjau dari perbaikan keterampilan, angket yang diberikan kepada 110 orang peserta didik diperoleh nilai rata-rata 3,79 dari skor maksimal 5 dengan tingkat pencapaian responden sebesar 75,82\% dalam kategori "baik". Artinya, peningkatan kemampuan keterampilan peserta didik sudah baik setelah mengikuti layanan bimbingan TIK.

Berdasarkan hasil penelitian, penggunaan media pembelajaran dengan memanfaatkan teknologi komputer sebagai fasilitasi guru TIK lebih efektif dibandingkan dengan tidak difasilitasi oleh guru TIK pada kurikulum sebelumnya. Hal ini disebabkan oleh penggunaan media pembelajaran tersebut memiliki berbagai kelebihan dan sangat memungkinkan bagi guru untuk membuat bahan ajar yang lebih menarik (Darimi, 2017; Muyaroah \& Fajartia, 2017). Hal ini didasari oleh hakikat belajar, yaitu dalam proses pembelajaran diperlukan pengarahan pandangan terhadap ilmu pengetahuan yang dibantu dengan teknologi yang difasilitasi oleh guru TIK untuk memudahkan siswa dalam belajar (Bervell et al., 2020; Hussein et al., 2021; Jang et al., 2021). Teknologi memiliki potensi yang sangat besar untuk mentransformasikan seluruh aspek pendidikan di sekolah untuk mencapai tujuan pembelajaran (Almusawi et al., 2021; Hashim, 2018). Evaluasi yang telah dilakukan dapat dipakai untuk melihat keefektifan bimbingan TIK dan sebagai dasar pertimbangan bagi pengembangannya. Evaluasi layanan bimbingan TIK efektif dan dapat membawa dampak positif terhadap peserta didik di sekolah. Evaluasi ditunjukkan dengan perolehan nilai pada peserta didik yang mendapatkan bimbingan TIK. Layanan bimbingan TIK yang dilakukan di sekolah dengan tujuan agar siswa mampu mengantisipasi pesatnya perkembangan teknologi, sehingga siswa dapat memanfaatkan TIK dengan baik dan benar sesuai keahliannya (Huda, 2020; Lubis, 2018). Dengan adanya fasilitasi guru TIK mengenai penggunaan teknologi komputer dalam pembuatan rapot, guru mata pelajaran akan merasa lebih mudah dan efektif dalam mengolah nilai (Bal-Taştan et al., 2018; Zabolotniaia et al., 2020).

Peran guru TIK dalam melaksanakan layanan bimbingan TIK terhadap guru dalam proses belajar mengajar memperoleh hasil yang sangat tinggi. Hasil analisis data yaitu 4 indikator yang memperoleh hasil sangat tinggi, yaitu pada indikator pengambangan sumber belajar, inidikator pengembangan media belajar, indikator proses pembelajaran, indikator pelaporan hasil belajar, serta pada indikator persiapan pembelajaran dan penilaian pembelajaran memperoleh hasil tinggi. Dengan adanya layanan bimbingan dapat membantu siswa (Gozali, 2020; Riansyah \& Wulandari, 2017). Materi atau bahan ajar mata pelajaran yang luas dapat menjadikan peserta didik mengalami kesulitan dalam proses belajar mengajar, sehingga antara siswa satu dan siswa lainnya akan mendapat pemahaman yang berbeda (Pennings et al., 2018; Todorescu et al., 2015). Oleh karena itu, dengan adanya layanan bimbingan TIK diharapkan mampu mempermudah guru mata pelajaran untuk menerangkan materi menggunakan media pembelajaran dengan memanfaatkan teknologi yang ada di sekolah.

Dengan adanya dampak yang diberikan dari fasilitasi guru TIK terhadap guru dalam proses belajar mengajar, ada kelebihan lain yang diperoleh. Di antaranya, proses penyampaian informasi akan lebih mudah dan luas, berkurangnya permasalahan yang dihadapi para guru dalam memanfaatkan teknologi komputer (Li et al., 2018; Tuma, 2021). Guru TIK maupun guru mata pelajaran lain khususnya pada mata pelajaran yang diujikan dalam ujian nasional dapat memperbarui informasi dan mengikuti perkembangan teknologi yang ada. Jadi, proses penyampaian materi lebih efektif dengan waktu singkat dan ketercapaian tujuan pembelajaran yang tinggi. 


\section{SIMPULAN}

Layanan bimbingan TIK dikategorikan baik. Berdasarkan model penelitian evaluasi Kirkpatrick dapat dilihat pada variabel yang menjadi instrumen pengukuran mempunyai hasil dalam kategori baik. Hal ini juga dapat dilihat dari fasilitas yang tersedia pada kategori baik, jadwal kegiatan layanan bimbingan sudah dalam kategori baik, dan materi yang diberikan sudah dalam kategori baik. Kategori baik yang didapat dari pelaksanaan bimbingan TIK dapat dijadikan pedoman untuk peningkatan layanan bimbingan TIK ke depannya agar pelaksanaan layanan bimbingan TIK lebih optimal dan bisa mencapai kategori sangat baik.

\section{DAFTAR RUJUKAN}

Almusawi, H. A., Durugbo, C. M., \& Bugawa, A. M. (2021). Innovation in Physical Education: Teachers' pPrspectives on Readiness for Wearable Technology Integration. Computers \& Education, 167. https://doi.org/10.1016/j.compedu.2021.104185.

Almutairi, T. S., \& Shraid, N. S. (2021). Teacher Evaluation by Different Internal Evaluators: Head of Departments, Teachers Themselves, Peers and Students. International Journal of Evaluation and Research in Education, 10(2), 588-596. https://doi.org/10.11591/ijere.v10i2.20838.

Amelia, R. P., Filiani, R., \& Herdi, H. (2017). Self-Efficacy terhadap Penggunaan Teknologi Informasi dan Komunikasi dalam Layanan Bimbingan dan Konseling pada Guru Bk/Konselor SMAN Jakarta Pusat. Insight: Jurnal Bimbingan Dan Konseling, 3(1). https://doi.org/10.21009/INSIGHT.031.18.

Andrian, \& Rusman. (2019). Implementasi Pembelajaran Abad 21 dalam Kurikulum 2013. Jurnal Penelitian Ilmu Pendidikan, 12(1). https://doi.org/10.21831/jpipfip.v12i1.20116. 14-23.

Astiningtyas, A. (2018). Kesiapan Guru Sekolah Dasar dalam Pelaksanaan Pembelajaran Tematik Integratif pada Kurikulum 2013. Primary: Jurnal Pendidikan Guru Sekolah Dasar, 7(1), 60. https://doi.org/10.33578/jpfkip.v7i1.5340.

Bal-Taştan, S., Davoudi, S. M. M., Masalimova, A. R., Bersanov, A. S., Kurbanov, R. A., Boiarchuk, A. V, \& Pavlushin, A. A. (2018). The Impacts of Teacher's Efficacy and Motivation on Student's Academic Achievement in Science Education among Secondary and High School Students. EURASIA Journal of Mathematics, Science and Technology Education, 14(6), 2353-2366. https://doi.org/10.29333/ejmste/89579.

Bdiwi, R., de Runz, C., Faiz, S., \& Cherif, A. A. (2019). Smart learning environment: Teacher's role in assessing classroom attention. Research in Learning Technology, 27, 1-14. https://doi.org/10.25304/rlt.v27.2072.

Bervell, B., Nyagorme, P., \& Arkorful, V. (2020). LMS-Enabled Blended Learning Use Intentions among Distance Education Tutors: Examining the Mediation Role of Attitude Based on TechnologyRelated Stimulus-Response Theoretical Framework (TR-SR-TF). Contemporary Educational Technology, 12(2), ep273. https://doi.org/10.30935/cedtech/8317.

Bhatia, M., Stewart, A. E., Wallace, A., Kumar, A., \& Malhotra, A. (2021). Evaluation of an In-Situ Neonatal Resuscitation Simulation Program Using the New World Kirkpatrick Model. Clinical Simulation in Nursing, 50. https://doi.org/10.1016/j.ecns.2020.09.006.

Bijani, M., Rostami, K., Momennasab, M., \& Yektatalab, S. (2018). Evaluating the Effectiveness of a Continuing Education Program for Prevention of Occupational Exposure to Needle Stick Injuries in Nursing Staff Based on Kirkpatrick's Model. Journal of the National Medical Association, 110(5). https://doi.org/10.1016/j.jnma.2017.11.002.

Buriak, S. E., \& Ayars, C. L. (2019). Evaluation of a Drug and Alcohol Safety Education Program in Aviation using InterruptedTtime Series and the Kirkpatrick Framework. Evaluation and Program Planning, 73. https://doi.org/10.1016/j.evalprogplan.2018.11.003.

Darimi, I. (2017). Teknologi Informasi dan KomunikasisSebagai Media Pembelajaran Pendidikan Agama Islam Efektif. Jurnal Pendidikan Teknologi Informasi, 1(2), 111-121. https://doi.org/10.1007/s11068-008-9037-4.

Enas Almanasreh, E., Moles, R., \& Timothy, M. (2019). Evaluation of Methods Used for Estimating Content Validity. Research in Social and Administrative Pharmacy, 15(2), 214-221. https://doi.org/10.1016/j.sapharm.2018.03.066.

Eugenia, Raymond, \& Leung, W. N. (2013). Ready for 21st-Century Education - Pre-Service Music Teachers Embracing ICT to Foster Student-Centered Learning. Procedia - Social and Behavioral Sciences, 73. https://doi.org/10.1016/j.sbspro.2013.02.047.

Farjad, S. (2012). The Evaluation Effectiveness of Training Courses in University by Kirkpatrick Model (Case Study: Islamshahr University). Procedia - Social and Behavioral Sciences, 46. https://doi.org/10.1016/j.sbspro.2012.05.573. 
Febriyanti. (2013). Article Kurikulum Pendidikan Tinggi di Era Globalisasi (Pergeseran dari Kurikulum Inti dan Institusional ke Kurikulum Berbasis Kompetensi). Ta'di Jurnal Pendidikan Islam, 18(2). https://doi.org/10.19109/tjie.v18i02.51.

Gozali, A. (2020). Bimbingan dan Konseling Berbasis Teknologi Informasi pada Masa PSBB ( Pembatasan Sosial Berskala Besar ). Jurnal Bimbingan Konseling Pendidikan Islam Coution: Journal of Counseling and Education Layanan, 1(2), 36-49. https://doi.org/10.47453/coution.v1i2.117.

Gracieux, F. Y. (2019). The Asian Sarcoma Consortium Sarcoma Preceptorship Program: A Program Evaluation Study Utilizing the Kirkpatrick Model (Level 1 and 2). Annals of Oncology, 30(9). https://doi.org/10.1093/annonc/mdz433.005.

Hanifa, R. (2018). EFL Published Materials: An Evaluation of English Textbooks for Junior High School in Indonesia. Advances in Language and Literary Studies, 9(2), 166. https://doi.org/10.7575/aiac.alls.v.9n.2p.166.

Harliawan, H. (2015). Penggunaan Media Pembelajaran Berbasis TIK untuk Meningkatkan Hasil Belajar IPS Kelas VIII J SMP Negeri 5 Singaraja. Ekuitas, 3(1). https://doi.org/10.23887/ekuitas.v3i1.12786.

Hashim, H. (2018). Application of Technology in the Digital Era Education. International Journal of Research in Counseling and Education, 1(2), 1. https://doi.org/10.24036/002za0002.

Huda, I. A. (2020). Perkembangan Teknologi Informasi dan Komunikasi ( TIK ) terhadap Kualitas Pembelajaran di Sekolah Dasar. Huda, Irkham Abdaul, 1(2), 143-149. https://doi.org/10.31004/jpdk.v1i2.622.

Hussein, B. R., Malik, O. A., Ong, W.-H., \& Slik, J. W. F. (2021). Reconstruction of Damaged Herbarium Leaves Using Deep Learning Techniques for Improving Classification Accuracy. Ecological Informatics, 61. https://doi.org/10.1016/j.ecoinf.2021.101243.

Jang, M., Aavakare, M., Nikou, S., \& Kim, S. (2021). The Impact of Literacy on Intention to Use Digital Technology for Learning: A Comparative Study of Korea and Finland. Telecommunications Policy, 45(7). https://doi.org/10.1016/j.telpol.2021.102154.

Li, J., Zhang, X., \& Hu, Z. (2018). The Design and Application of Flip Classroom Teaching Based on Computer Technology. International Journal of Emerging Technologies in Learning, 13(10), 95107. https://doi.org/10.3991/ijet.v13i10.9453.

Lubis, A. H. (2018). Integrasi TIK dalam Pengajaran Bahasa Inggris di Indonesia Abad Ke-21: Mitos dan $\begin{array}{llll}\text { Realita. } & \text { Cakrawala Pendidikan, } & 37(1), & 11-21 .\end{array}$ https://journal.uny.ac.id/index.php/cp/article/view/16738/pdf.

Maharani, Y. S. (2015). Efektivitas Multimedia Pembelajaran Interaktif Berbasis Kurikulum 2013. Indonesian Journal of Curriculum and Educational Technology Studies, 3(1), 31-40. https://doi.org/10.15294/ijcets.v3i1.8683.

Mellom, P. J., Straubhaar, R., Balderas, C., Ariail, M., \& Portes, P. R. (2018). “They Come with Nothing:" How Professional Development in a Culturally Responsive Pedagogy Shapes Teacher Attitudes towards Latino/a English Language Learners. Teaching and Teacher Education, 71, 98-107. https://doi.org/10.1016/j.tate.2017.12.013.

Mulyadin. (2016). Implementasi Kebijakan Pembelajaran Tematik Terpadu Kurikulum 2013 di SDN Kauman 1 Malang dan SD Muhammadiyah 1 Malang. Jurnal Pendidikan Edutama, 3(2), 31-48. https://doi.org/http://dx.doi.org/10.30734/jpe.v3i2.35.

Mulyanto, B. S., Sadono, T., Koeswanti, H. D., Dasar, S., Wonodoyo, N., Tengah, J., Kristen, U., Wacana, S., \& Tengah, J. (2020). Evaluation of Critical Thinking Ability with Discovery Lerning Using Blended Learning Approach in Primary School. Journal of Educational Research and Evaluation, 9(2), 7884. https://doi.org/10.15294/jere.v9i2.46135.

Muyaroah, \& Fajartia. (2017). Pengembangan Media Pembelajaran Berbasis Android dengan Menggunakan Aplikasi Adobe Flash CS 6 pada Mata Pelajaran Biologi. Innovative Journal of Curriculum and Educational Technology., 6(2). https://doi.org/10.15294/ijcet.v6i2.19336.

Nasihin, S. (2016). Implementasi Kurikulum 2013 di MTs Yaqin 1 Kwang Rundun Kecamatan Jerowaru (Masalah dan Solusinya). Jurnal Studi Keislaman Dan Ilmu Pendidikan, 4(1), 56-86. https://doi.org/10.36088/palapa.v4i1.8.

Pennings, H. J. M., Brekelmans, M., Sadler, P., Claessens, L. C. A., van der Want, A. C., \& van Tartwijk, J. (2018). Interpersonal Adaptation in Teacher-Student Interaction. Learning and Instruction, 55, 41-57. https://doi.org/10.1016/j.learninstruc.2017.09.005.

Peralbo-Uzquiano, M., Fernández-Abella, R., Durán-Bouza, M., José-Manuel Cotos-YáñezBrenlla-Blanco, J.C., \& Brenlla-Blanco, J.-C. (2020). Evaluation of the Effects of a Virtual Intervention Programme on Cognitive Flexibility, Inhibitory Control and Basic Math Skills in Childhood Wducation. Computers \& Education, 159. https://doi.org/10.1016/j.compedu.2020.104006. 
Rahmawati, Budiyono, \& Wardi. (2017). Pengembangan Modul Pembelajaran Digital Berbasis Visual Basic for Application (VBA) PowerPoint. Indonesian Journal of Curriculum and Educational Technology, 5(1). https://doi.org/https://doi.org/10.15294/ijcets.v5i1.14248.

Riansyah, H., \& Wulandari, W. (2017). Layanan Bimbingan Kelompok dalam Meningkatkan Interaksi Sosial Siswa. Teraputik: Jurnal Bimbingan Dan Konseling, 1(1). https://doi.org/10.26539/1110.

Sakthi, T., \& Moshi, A. A. M. (2021). Effectiveness Measurement Study on Entrepreneurship Awareness Camp for Technical Education Students Using Kirkpatrick's Model. Materials Today: Proceedings, 45(2). https://doi.org/10.1016/j.matpr.2020.08.419.

Sanjiwana, Pudjawan, \& Margunayasa. (2015). Analisis Sikap Sosial Siswa Kelas V pada Pembelajaran dengan Kurikulum 2013. Jurnal PGSD Universitas Pendidikan Ganesha Jurusan PGSD, 3(1), 11-18. https://doi.org/10.23887/jjpgsd.v3i1.5631.

Savul, S., Ikram, A., Khan, M. A., \& Khan, M. A. (2021). Evaluation Of Infection Prevention and Control Training Workshops Using Kirkpatrick's Model. International Journal of Infectious Diseases, 1. https://doi.org/10.1016/j.ijid.2021.09.005.

Susanti, N. Y., Trapsilasiwi, D., \& Kurniati, D. (2015). Analisis Tingkat Kognitif Uji Kompetensi pada Buku Sekolah Elektronik (BSE) Matematika SMP/MTs Kelas VII Kurikulum 2013 Berdasarkan Taksonomi Bloom. Kreano Jurnal Matematika Kreatif-Inovatif, 6(1). https://doi.org/10.15294/kreano.v6i1.4509.

Tanudjaya, C. P., \& Doorman, M. (2020). Examining Higher Order Thinking in Indonesian Lower Secondary Mathematics Classrooms. Journal on Mathematics Education, 11(2), 277-300. https://doi.org/10.22342/jme.11.2.11000.277-300.

Tempelaar, D. (2019). Assessment \& Evaluation in Higher Education Supporting the Less-Adaptive Student: The Role of Learning Analytics, Formative Assessment and Blended lLarning. Assessment and Evaluation in Higher Education, 45(4). https://doi.org/10.1080/02602938.2019.1677855.

Todorescu, L., Popescu-mitroi, M., \& Greculescu, A. (2015). Students ' Views on the Teacher as An Information Provider Students ' Views on the Teacher as An Information Provider. Procedia Social and Behavioral Sciences, 184-189. https://doi.org/10.1016/j.sbspro.2015.07.121.

Tseng, S. (2021). The Influence of Teacher Annotations on Student Learning Engagement and Video Watching Behaviors. International Journal of Educational Technology in Higher Education, 18(1), 1-17. https://doi.org/10.1186/s41239-021-00242-5.

Tuma, F. (2021). The Use of Educational Technology for Interactive Teaching in Lectures. Annals of Medicine and Surgery 62, 231-235. https://doi.org/10.1016/j.amsu.2021.01.051.

Wu, W. H., Kao, H. Y., Wu, S. H., \& Wei, C. W. (2019). Development and Evaluation of Affective Domain Using Student's Feedback in Entrepreneurial Massive Open Online Courses. Frontiers in Psychology, 10(MAY). https://doi.org/10.3389/fpsyg.2019.01109.

Yongliang, T., Hu, L., Jiao, Y., Mingqiang, L., \& Guanghui, W. (2015). Evaluation of Simulation-Based Training for Aircraft Carrier Marshalling with Learning Cubic and Kirkpatrick's Models. Chinese Journal of Aeronautics, 28(1). https: //doi.org/10.1016/j.cja.2014.12.002.

Zabolotniaia, M., Cheng, Z., Dorozhkin, E., \& Lyzhin, A. (2020). Use of the LMS Moodle for an Effective Implementation of an Innovative Policy in Higher Educational Institutions. International Journal of $\begin{array}{lllll}\text { Emerging Technologies in Learning } & 172 .\end{array}$ https://doi.org/10.3991/ijet.v15i13.14945. 